\title{
A sabedoria da ignorância: sobre $O$ crítico ignorante, de Daniele Avila Small
}

The wisdom of ignorance: on O crítico ignorante by Daniele Avila Small

\section{Ana Maria de Bulhões-Carvalho}

Ana Maria de Bulhões-Carvalho

Professora associada do Departamento de Teoria do Teatro e do Programa de Pós-Graduação em Artes Cênicas da Universidade Federal do Rio de Janeiro e pesquisadora do CNPq

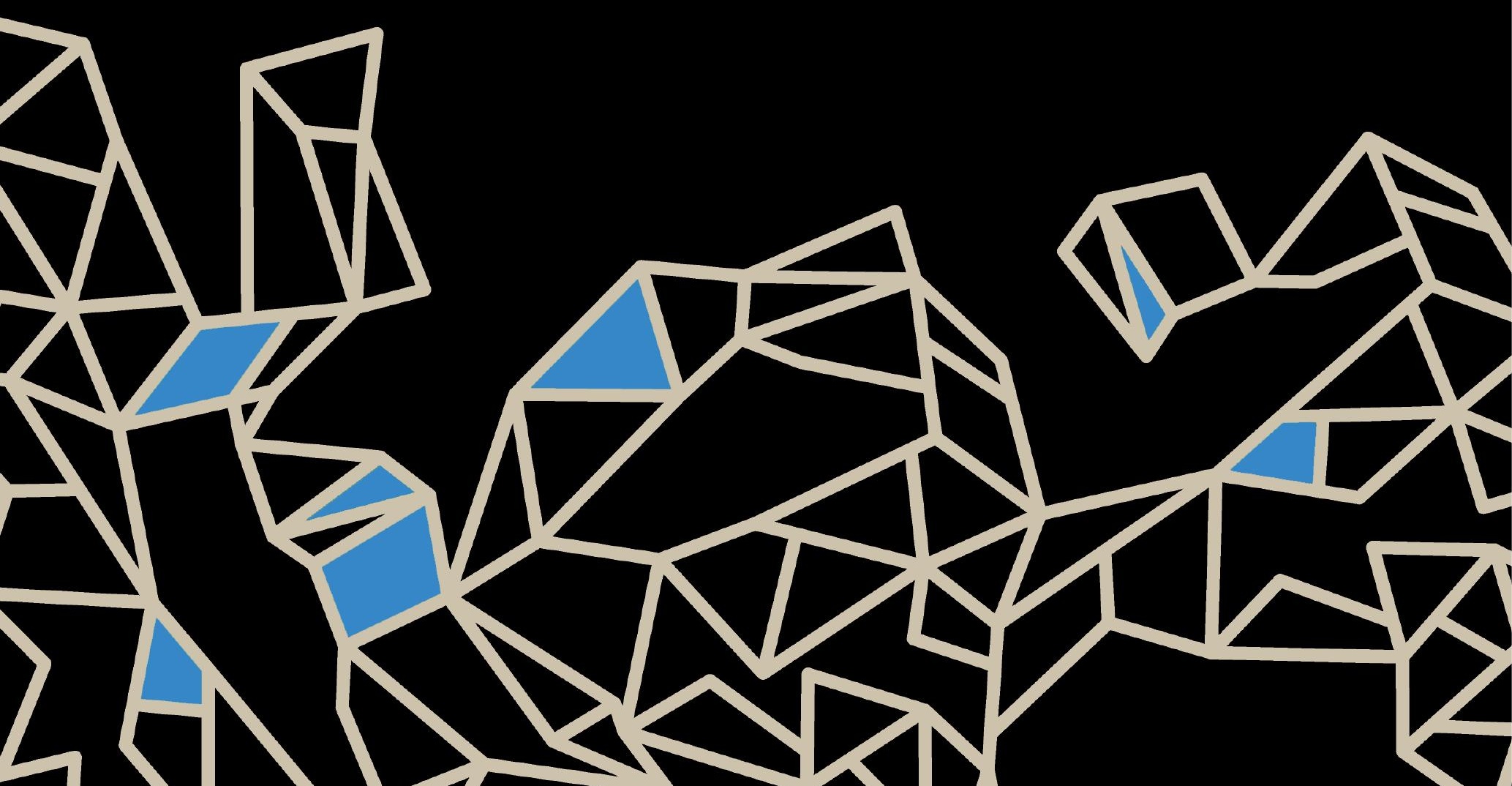




\section{A sabedoria da ignorância}

Daniele Avila Small, na apresentação do livro, chama modestamente seu discurso a respeito do que nomeou "o crítico ignorante" de "apontamentos", não sem acrescentar a essa falsa simplificação a ressalva de que tem consciência clara do quadro de "condições e perspectivas" em que se situa seu estudo, e cola essas qualidades a uma situação de enfrentamento. As condições prévias e as perspectivas que abre constituem territórios intelectuais que mapeia, discute, assimila ou refuta de modo a se permitir aventurar-se na exploração do objeto de estudo que a seduz e desafia: a crítica teatral.

Armando-se de pressupostos teóricos operativos que lhe parecem suficientemente sustentáveis, parte para o delineamento, a busca e a realização de perspectivas que possam trazer um olhar renovado para o campo da crítica. Encontrou ferramentas para este embate nos escritos de Jacques Rancière em torno do conceito de emancipação - que o filósofo francês desentranhou, por sua vez, do que aprendeu com a pedagogia de Joseph Jacotot, encontro que expõe como proposta e provocação em seu livro $O$ mestre ignorante: cinco lições sobre a emancipação intelectual (JACOTOT, 2007), lugar de onde vislumbra uma inversão lógica na relação com o mundo e o saber tal como Jacotot propusera à Pedagogia no início do século XIX: o saber transmitido e explicado embrutece, pois sujeita o aluno à dependência de seu esclarecimento e, diferente do imaginado, torna o aluno ser dependente, 0 que apenas reforça e garante a função do mestre como explicador. Revertida esta lógica, por efeito de um método aplicado à força do acaso de um "empirismo desesperado" (RANCIÈRE, 2007, p. 18), Jacotot, obrigado na condição de exilado a aceitar uma posição de mestre de francês em escola na Holanda sem conhecer o holandês, confronta o fato de que, após um tempo de experiência, "alguns estudantes [holandeses] se ensinaram a falar e escrever em francês sem o socorro de suas explicações" (RANCIÈRE, 2007, p. 26). Fizera uma aposta no escuro e lograra bom resultado, o fato de não saber uma palavra de holandês não afetou o aprendizado que, com auxílio de um intérprete, desfiara os alunos a fazerem por si sós, por meio de uma edição bilíngue do livro Telêmaco, de Fénelon, escolhido pelo fato de ser uma edição em francês e flamengo. Rancière aposta em Jacotot e passa adiante a experiência: 
[...] sem perceber, ele [Jacotot] os havia feito descobrir o que ele próprio com eles descobrira: todas as frases e, por conseguinte, todas as inteligências que as produzem são de mesma natureza. Compreender não é mais do que traduzir, isto é, fornecer o equivalente de um texto, mas não de sua razão. Nada há atrás da página escrita, nenhum fundo duplo que necessite do trabalho de uma inteligência outra, a do explicador; nenhuma língua do mestre, nenhuma língua cujas palavras e frases tenham o poder de dizer a razão das palavras e frases de um texto. (RANCIÈRE, 2007, p. 27)

O corolário da descoberta de Jacotot em relação a seus alunos holandeses parece simples e, talvez, óbvio: "uma palavra humana Ihes foi dirigida, a qual querem reconhecer e à qual querem responder [...] sob o signo da igualdade" (RANCIÈRE, 2007, p.29). O novo método de Jacotot não só emancipara os discípulos da dependência do mestre explicador, como fizera deles seus iguais - iguais no uso da inteligência, na capacidade de compreender por si. Quer dizer: o "método da igualdade era, antes de mais nada, um método da vontade" (RANCIÈRE, 2007, p. 30). Jacotot havia comprovado isso: o bom resultado viera do encontro da vontade e da inteligência, uma vontade que se submete e uma inteligência que se liberta. A nova pedagogia não contrapunha mais ciência e ignorância, mas embrutecimento (da explicação) e emancipação (de inteligência livre). Surge então o termo paradoxal proposto por Rancière, o mestre ignorante, ou o mestre emancipador, que acredita que se "pode ensinar o que se ignora" (RANCIÈRE, 2007, p. 34), em contraposição ao mestre embrutecedor ou mestre explicador.

O emancipado é aquele que conhece o "verdadeiro poder do espírito humano": o "ignorante aprenderá sozinho o que o mestre ignora, se o mestre acredita que ele o pode, e o obriga a atualizar sua capacidade" (RANCIÈRE, 2007, p. 34), e desse modo foge ao círculo da impotência, o estabelecido como verdadeiro: aos que sabem acorrem os que não sabem. Revertida essa ordem, estabelece-se o círculo da potência intelectual a ser acessada pela vontade. "Ele saberá que pode aprender porque a mesma inteligência está em ação em todas as produções humanas, que um homem sempre pode compreender a palavra de um outro homem" (RANCIÈRE, 2007, p. 37). Explicando Jacotot, Rancière oferece um novo saber para a educação do indivíduo: "não se tratava aí de um método para instruir o povo, mas da graça a ser 
anunciada aos pobres: eles podiam tudo o que pode um homem. Ele proclamou [...] o Ensino Universal: aprender qualquer coisa e a isto relacionar todo o resto, segundo o princípio de que todos os homens têm igual inteligência" (RANCIÈRE, 2007, p. 38).

Ora, pois Daniele Avila Small, ainda estudante de Teoria do Teatro da UNIRIO, para sua monografia de final de curso, comprovou o que dissera Jacotot duzentos anos antes, como princípio de seu método universal: "É o discípulo que faz o mestre" (p. 39). E não precisou de muito mais além da coragem de se aventurar em deslizar esse ensinamento para o campo que desejava, para a relação de poder e saber que a desafiava, isto é, "aplicar o princípio de Jacotot como princípio da crítica, emancipação como condição do espectador" (p. 26).

Parece que não, mas esse campo sofre com os mesmos preconceitos e pressupostos restritivos que a pedagogia antes de Jacotot (façamos de conta que mudou). Trocando o verbo aprender, relativo ao ensino, pelo verbo apreender, relativo à observação, tal como o discípulo de Jacotot, o espectador, nessa aposta emancipatória de Daniele Small, pode dedicar atenção à obra que quer examinar, e "expressar suas opiniões, buscar, tatear, comparar, verificar, traduzir em palavras a sua experiência até que não possa mais repetir a preguiçosa ladainha do 'não entendi'” (p. 28). Essa vai ser a aposta, a atitude e o método do crítico ignorante, aquele que desafia um suposto saber superior e volta sua atenção esforçada para o destrinçamento do espetáculo teatral que o instiga, ainda que isso the exija esforço redobrado para vencer barreiras. O que ele fará é buscar palavras e frases que registrem os pensamentos que formou sobre a obra. Diz Daniele: "a atividade da crítica e a da escrita teórica são, antes de mais nada, a transformação de pensamentos em palavras e frases" (p. 31).

A lógica do método universal, de que "bastaria aprender a ser homens iguais em uma sociedade desigual" (p. 39) parece ajustar-se bem à proposta, como atividade que, ainda que atinja o coletivo, faz-se de modo individual. "O princípio de igualdade defendido por Jacotot não trata [...] de construir uma sociedade de iguais" (p. 39). A esse respeito não é demais lembrar o que diz Rancière nas palavras de Costa Netto, citado por Daniele Small: 
Uma das coisas importantes que Jacotot diz é que é preciso separar as razões, que um emancipador não é um professor, [no sentido de que deve explicar], que um emancipador não é um cidadão [no sentido de que com sua ação vai emancipar um Estado]. Pode ser ao mesmo tempo professor, cidadão e emancipador, mas não pode sê-lo em uma lógica única (p. 39).

Dado o princípio, fundamento de nova postura crítica, O crítico ignorante dedica seus próximos capítulos - a partir do método negativo que Daniele, leitora de Adorno, tão bem assimilou de "O ensaio como forma" - dizem primeiro de uma tradição do pensamento crítico no qual esta nova postura vai se inserir a se contrapor à ideia de falência da crítica (p. 42) ${ }^{1}$. É da própria Daniele a tradução do ensaio "O espectador emancipado", que ela publicou no site Questão de crítica, importante porque neste texto Rancière faz "a ponte entre a discussão das relações de professor e aluno e de artista e público" (p. 43), a partir da qual o espectador é aproximado do aluno de Jacotot pela afirmação do princípio de igualdade (de inteligência). Estabelecendo uma reconfiguração do mestre pelo artista, Rancière estabelecera a primeira ponte. Daniele, ao supor o crítico nesta posição em que Rancière colocara o artista, estabelece a segunda ponte. O processo será semelhante ao ocorrido com a pedagogia: onde o sistema pede explicação para esclarecimento, mantendo a hierarquia mestre-discípulo, percebe-se a hierarquia crítico-espectador. Revertendo este quadro, mantendo a lógica de Jacotot, chega-se ao crítico ignorante e ao espectador emancipado.

O importante na leitura do texto produzido por Daniele Small é a sua fabulação mesma, o passo a passo com que trama a transposição de uma lógica para outra, sem pressa, generosamente socializando com o leitor os meandros do seu pensamento. Não para explicar e cair em contradição com o método que defende - aí está o segredo, arrisco dizer, da "negociação teórica meio complicada" do subtítulo. Daniele não explica, mas, ainda surpresa com a possibilidade de parear suas ideias com as de Rancière, justifica a remoldu-

1 É preciso alertar o leitor para o fato de Daniele citar alguns textos de Rancière conforme fontes originais, em língua francesa e inglesa, a partir de traduções que ela mesma realizou para o trabalho. Os referidos textos, tanto "O espectador emancipado" quanto "Desventuras do pensamento crítico" e "Paradoxos da arte política" integram o volume $O$ espectador emancipado (2014). Por isso as traduções citadas pela autora e as disponíveis em língua portuguesa na publicação a que refiro agora não coincidem. 
ração do mestre, cujos textos admira e quer de algum modo homenagear na defesa que faz do novo espectador, um espectador que reconheça seu estar no mundo e reivindique sua "maioridade" de indivíduo. É esse espectador que abala a partilha preestabelecida entre superiores e inferiores. Nessa nova relação todos saem ganhando, o artista e o espectador, porque revistos na sua condição individual, em posição de equivalência intelectual.

Mas vale a pena ler no próprio texto de $\mathrm{O}$ crítico ignorante a riqueza de detalhes com que cada um desses aspectos do comportamento humano é visto e exemplificado; acompanhar as linhas de fuga que os capítulos oferecem para repensar a relação entre a obra e o espectador. Isso a autora ainda revê numa aproximação histórica das tensões entre a crítica corretiva e o ideal de emancipação, conforme a levam os críticos da cultura, como Terry Eagleton e Reinhart Koselleck; ou a avaliação sobre o ensaio de Foucault sobre a crítica como atitude, cujas leituras acompanha em seus meandros e citações, relidas e revistas sem que se perca o foco principal. Ou o capítulo que a leitora de Adorno dedica à apreciação da forma do ensaio.

Com certeza a leitura atenta do livro $O$ crítico ignorante ratifica a autora, Daniele Avila Small, como uma crítica ignorante. O que ela mesma confirma, quando defende uma função para a crítica como aquela que se aventura no "exercício público do livre jogo do pensamento que faz associações e oferece a sua contratradução para as obras" e se coloca sutilmente como "estímulo à conversa sobre o que não tem função predeterminada ou utilidade definida". É uma provocação inegável, mas um convite imperdível.

\section{Referências bibliográficas}

JACOTOT, J. O mestre ignorante: cinco lições sobre a emancipação intelectual. 2. ed. Belo Horizonte: Autêntica, 2007

RANCIÈRE, J. O espectador emancipado. Tradução de Ivone Benedetti. 2. ed. São Paulo: Martins Fontes, 2014.

SMALL, D. A. O crítico ignorante. Rio de Janeiro: 7Letras, 2015.

Recebido em 26/10/2015

Aprovado em 26/10/2015

Publicado em 21/12/2015 